\title{
Exercise response in 404 young men with asthma: no evidence for a late asthmatic reaction
}

Jouko Karjalainen

\begin{abstract}
As the existence of a late reaction in exercise induced asthma is controversial, peak expiratory flow (PEF) was measured for up to 13 hours after a running test in 404 consecutive young male army conscripts undergoing assessment of their asthma. In 294 subjects $(73 \%)$ the immediate post-exercise fall in PEF was $10 \%$ or more; the mean (SD) fall in PEF in this group was $27 \%(15 \%)$. Nine patients with exercise induced asthma had a fall in PEF of $20 \%$ or more 4-13 hours after the exercise test. In these possible "late responders," however, the change in PEF 4-13 hours after exercise was similar to the change in PEF on control days before and after the exercise day, and the lowest PEF during this period was similar to the lowest measurements on the control days. These nine subjects showed pre-exercise bronchodilatation. Their pre-exercise PEF, from which the percentage fall in PEF was calculated, was $24 \%(9 \%)$ higher than the mean PEF level on control days. This study supports the view that what appears to be a "late asthmatic reaction" after exercise is an artefact. Spontaneous within day fluctuation in pulmonary function, pre-exercise bronchodilatation, and the fact that airflow obstruction persists after the early postexercise response may give a false impression of an exercise induced late asthmatic response in patients with labile airways.
\end{abstract}

A late asthmatic response has been well documented as following the early bronchoconstriction response to allergen exposure in individuals with asthma. The existence of a similar delayed response after exercise is controversial. $^{12}$ In exercise induced asthma bronchoconstriction reaches its peak about 10 minutes after exertion and spontaneous recovery is usually complete within an hour. Bierman et al found that this immediate response was followed in some patients by further bronchoconstriction three to eight hours after exercise. ${ }^{3}$ This study was reported only in abstract form, but this biphasic response has been reported in other studies ${ }^{4-6}$ in up to a third of patients with exercise induced asthma. ${ }^{4}$ Verifying the occurrence of late bronchoconstriction after exercise poses methodological problems, however, because of intrinsic bronchial lability in asthmatic patients, especially those with more severe asthma, in whom the late response is most often found. Recently Rubinstein et al showed that the late bronchoconstriction seen after exercise may be an epiphenomenon, bearing no relation to preceding exercise, as corresponding changes in pulmonary function were found on control days without an exercise challenge. ${ }^{7}$ Their study was made on selected patients, however, and control days always followed exercise days, so that a late response after exercise could have influenced pulmonary function on the following control day. ${ }^{89}$

The purpose of the present study was to assess the occurrence of immediate and late responses to exercise in a large number of unselected patients who were consecutively admitted to hospital for evaluation of their asthma.

\section{Methods}

PATIENTS

The patients were young male army conscripts, with $\cdot a$ mean age of 21 (range 18-28) years. They were consecutively admitted to the Central Military Hospital, Helsinki, for an assessment of their fitness for military service because of stable or aggravated asthma or, in patients who had developed suggestive symptoms during service, for confirmation of the diagnosis of asthma. The diagnosis of asthma was based on a history of asthmatic symptoms (wheezing or prolonged non-infectious cough) and the demonstration of bronchial hyperreactivity to histamine or an exercise challenge or both. Of the 424 asthmatic men who underwent exercise testing from October 1985 to February 1989, 20 were excluded from the study: 12 left the hospital and eight were given a bronchodilator before postexercise pulmonary function could be assessed. In the 404 asthmatic subjects studied the mean (SD) forced expiratory volume in one second $\left(\mathrm{FEV}_{1}\right)$ was $88 \%(11 \%)$ predicted, the blood eosinophil count was $0.28(0.21) \times 10^{9} 1$, and the geometric mean serum concentration of total IgE was 215 (range 25-6500) kU/l. Eighty five per cent of the patients had at least one positive reaction in skinprick tests; $35 \%$ were smokers. Only $24 \%$ of the patients took regular daily asthma medication before they entered the study. Others had no medication or used inhaled bronchodilators when needed.

In Finland most men with mild or even moderate asthma enter compulsory military service and serve in a lower fitness class. Only asthmatic men requiring daily multidrug regimens are usually exempted. The study population does not therefore include patients with severe active disease of long duration. 


\section{STUDY DESIGN}

The patients were admitted to hospital for at least three days. All medication was withdrawn for 12 hours and theophylline preparations for 48 hours before the study. All patients underwent an exercise test, usually on the second day of their hospital stay. No exercise test was administered if the patient had bronchial obstruction considered to require immediate treatment $\left(\mathrm{FEV}_{1}\right.$ less than $70 \%$ predicted) or if less than three weeks had elapsed since a respiratory infection. Peak expiratory flow (PEF) was monitored three times daily (at 0600,1300 , and 1800 hours) while they were in hospital.

\section{EXERCISE TESTING}

An eight minute running test was performed out of doors on a 150 metre circular track, between 0930 and 1100 hours. Air temperature ranged from $-19^{\circ} \mathrm{C}$ to $+30^{\circ} \mathrm{C}$ on the test days. The running speed was adjusted by monitoring the subjects' heart rate with a Sport Tester TM PE 3000 heart rate meter (Polar Electro Ky, Kempele, Finland). Heart rate is displayed on a wristwatch like recorder as the average of 16 consecutive beats. Heart rate values were collected at 15 second intervals in the memory of the recorder and analysed later. Subjects raised their heart rate to $85 \%$ of the predicted maximal rate ( 170 beats/min in this age group) during a two minute warm up and maintained this rate for the remaining six minutes of the test.

PEF values were measured just before the run and immediately and 5, 10, 20, and 30 minutes after the test, with further measurements $1,4,7,10$, and 12-13 hours after the test. All but the first postexercise PEF measurements were made indoors. Three measurements were obtained on each occasion and the highest value was taken as the result.
The same Wright's peak flow meter was used in the exercise test and for daily follow up measurements in each patient. All subjects had a PEF value measured at 0600 hours, about four hours before the test. The following definitions were used:

Percentage change in PEF (\%PEF): the difference between pre-exercise and postexercise PEF expressed as a percentage of pre-exercise PEF.

Early asthmatic response: The maximal \% PEF between five and 30 minutes postexercise: subjects with a value exceeding $10 \%$ were considered to have exercise induced asthma. ${ }^{10}$ Late asthmatic response: A \% PEF of $20 \%$ or more in one or more measurements between four and 13 hours after exercise. ${ }^{7}$

CONTROL DAYS

The three times daily PEF measurements were used to monitor pulmonary function on nonexercise days. The PEF measurements at 1300 and 1800 hours were made at almost the same time of day as the PEF measurements four and seven hours after the exercise challenge. Measurements from one control day before and one control day after the exercise test day were chosen on the assumption that the patient had been without medication for at least 12 hours before the PEF measurements.

\section{STATISTICAL METHODS}

The significance of the fall in PEF between four and seven hours after exercise was estimated by comparing these values with the corresponding change in PEF measurements on control days (taken at 1300 and 1800 hours respectively). Ninety five per cent confidence intervals (CI) for the changes were calculated. Pre-exercise PEF was compared with PEF on control days in a similar way.
Figure 1 Mean peak expiratory flow curves in 404 asthma patients divided in groups on the basis of severity of the immediate postexercise reaction. On control days, both before and after the exercise day, $P E F$ corresponds to the PEF measured from 4 to 13 hours after exercise. 110 subjects with PEF fall of $\left\langle 10^{\prime \prime} \% ; \leftrightarrow 138\right.$ subjects with PEF fall of $10-19 \%$; 57 subjects with PEF fall of 20-29\%,

43 subjects with PEF fall of $30-39 \% ; 1$ subjects with PEF fall of $40-49 \% ; \Delta 25$ subjects with PEF fall of $\geqslant 50 \%$.

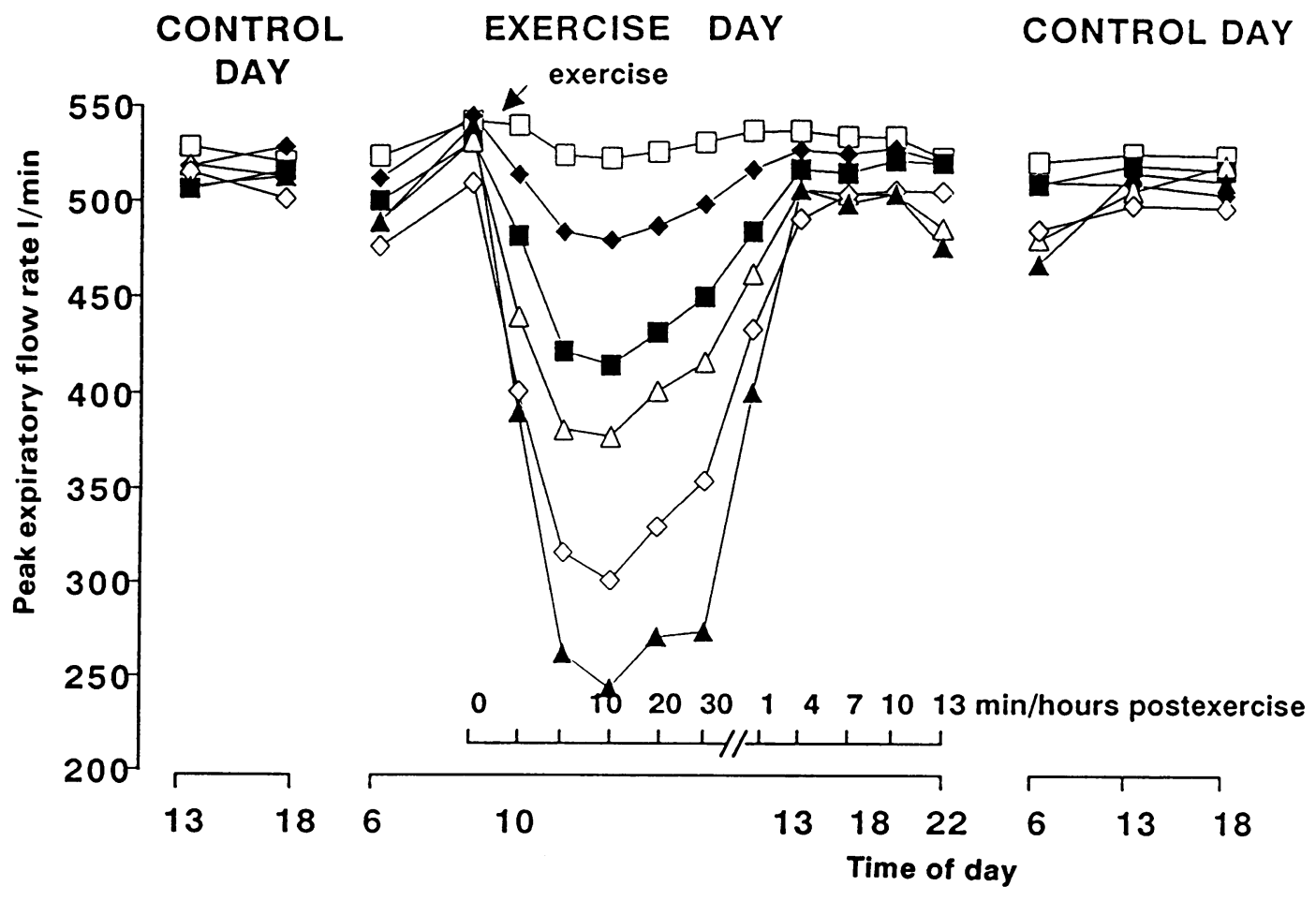


Table 1 Peak expiratory flow (PEF) immediately before exercise and the minimum levels during the potential late response period and during the control period in 404 men with asthma according to the magnitude of the immediate postexercise fall in PEF

\begin{tabular}{|c|c|c|c|c|c|}
\hline \multirow[b]{2}{*}{$\begin{array}{l}\text { Immediate } \\
\text { reaction } \\
\text { ": fall }\end{array}$} & \multirow[b]{2}{*}{$\begin{array}{l}\text { No of } \\
\text { patients }\end{array}$} & \multirow[b]{2}{*}{$\begin{array}{l}\text { Air temperature } \\
\text { during test } \\
\left({ }^{\circ} \mathrm{C}, \text { mean }(S D)\right)\end{array}$} & \multicolumn{3}{|c|}{$P E F(l / \min$, mean $(S D))$} \\
\hline & & & $\begin{array}{l}\text { Before } \\
\text { exercise }\end{array}$ & $\begin{array}{l}\text { Minimum } \\
4-13 h \text { after } \\
\text { exercise }\end{array}$ & $\begin{array}{l}\text { Minimum } \\
\text { during control } \\
- \text { days }\end{array}$ \\
\hline $\begin{array}{r}<10 \\
10-19 \\
20-29 \\
30-39 \\
40-49 \\
>50\end{array}$ & $\begin{array}{r}110 \\
138 \\
57 \\
43 \\
31 \\
25\end{array}$ & $\begin{array}{l}7(10) \\
5(10) \\
4(11) \\
2(12) \\
1(10) \\
0(10)\end{array}$ & $\begin{array}{l}541(61) \\
541(65) \\
531(57) \\
531(65) \\
509(84) \\
540(64)\end{array}$ & $\begin{array}{l}519(64) \\
504(77) \\
498(54) \\
481(77) \\
473(75) \\
464(87)\end{array}$ & $\begin{array}{l}508(62) \\
491(70) \\
481(61) \\
468(80) \\
453(71) \\
463(71)\end{array}$ \\
\hline
\end{tabular}

\section{Results}

The early postexercise fall in PEF exceeded $10 \%$ in 294 of the 404 patients with asthma $(73 \%)$. In those patients considered to have exercise induced asthma the mean fall in PEF was $27 \%(15 \%)$. Changes in PEF up to 2200 hours are shown in relation to the magnitude of the early response in figure 1 . No group shows a clear-cut further fall between 4 and 13 hours of exercise. PEF levels during this time were similar to levels measured on control days (fig 1 and table 1).

Nine of the 294 subjects with exercise induced asthma (3\%) had a fall in PEF of $20 \%$ or more for at least one measurement between four and 13 hours after the exercise test. The exercise responses in this potential late responder group are examined in figure 2 . The early response in this group was more severe (mean (SD) fall in PEF $40 \%(17 \%)$ ) than in the other subjects $(26 \%(14 \%))$ and the PEF had not returned to the pre-exercise level by $2200 \mathrm{~h}$. The PEF levels were similar to the PEF on the control days, however, and the postexercise PEF values at 4 and 7 hours did not differ significantly from the corresponding PEF measurements on control days. The nine possible "late responders" did not show any consistent pattern of fall in PEF values and their control day measurement showed greater fluctuations than the other subjects. The differences between the four hour postexercise PEF and corresponding PEF on control days were $-25 \mathrm{l} / \mathrm{min}(95 \% \mathrm{CI}-82$ to $32 \mathrm{l} / \mathrm{min}$ ) for the control day before exercise and $-9 \mathrm{l} / \mathrm{min}(95 \%$ CI -99 to $791 / \mathrm{min}$ ) for control day after the test. The difference between the seven hour postexercise PEF and corresponding PEF on control days before and after the test were -20 $1 / \mathrm{min}(95 \% \mathrm{CI}-52$ to $12 \mathrm{l} / \mathrm{min})$ and $-31 \mathrm{l} / \mathrm{min}$ (95\% CI -103 to $411 / \mathrm{min}$ ) respectively. In these nine subjects the pre-exercise $P E F$ value was significantly higher than the mean PEF level on control days- $24 \%(9 \%)$ or $76 \mathrm{l} / \mathrm{min}$ (95\% CI 39 to $1131 / \mathrm{min}$ ) compared with $4 \%$ $(1 \%)$ in the other subjects with exercise induced asthma (fig 2).

\section{Discussion}

This study shows that in a group of over 400 asthma patients no consistent pattern of "exercise induced late asthmatic reaction" could be
Figure 2 Mean ( $S D$ ) postexercise peak expiratory flow (PEF) curves of nine possible "late responders" with a fall in PEF of $20 \%$ or more from 4 to 13 hours postexercise ( $)$, and in 285 other patients with exercise induced asthma $1: 1$

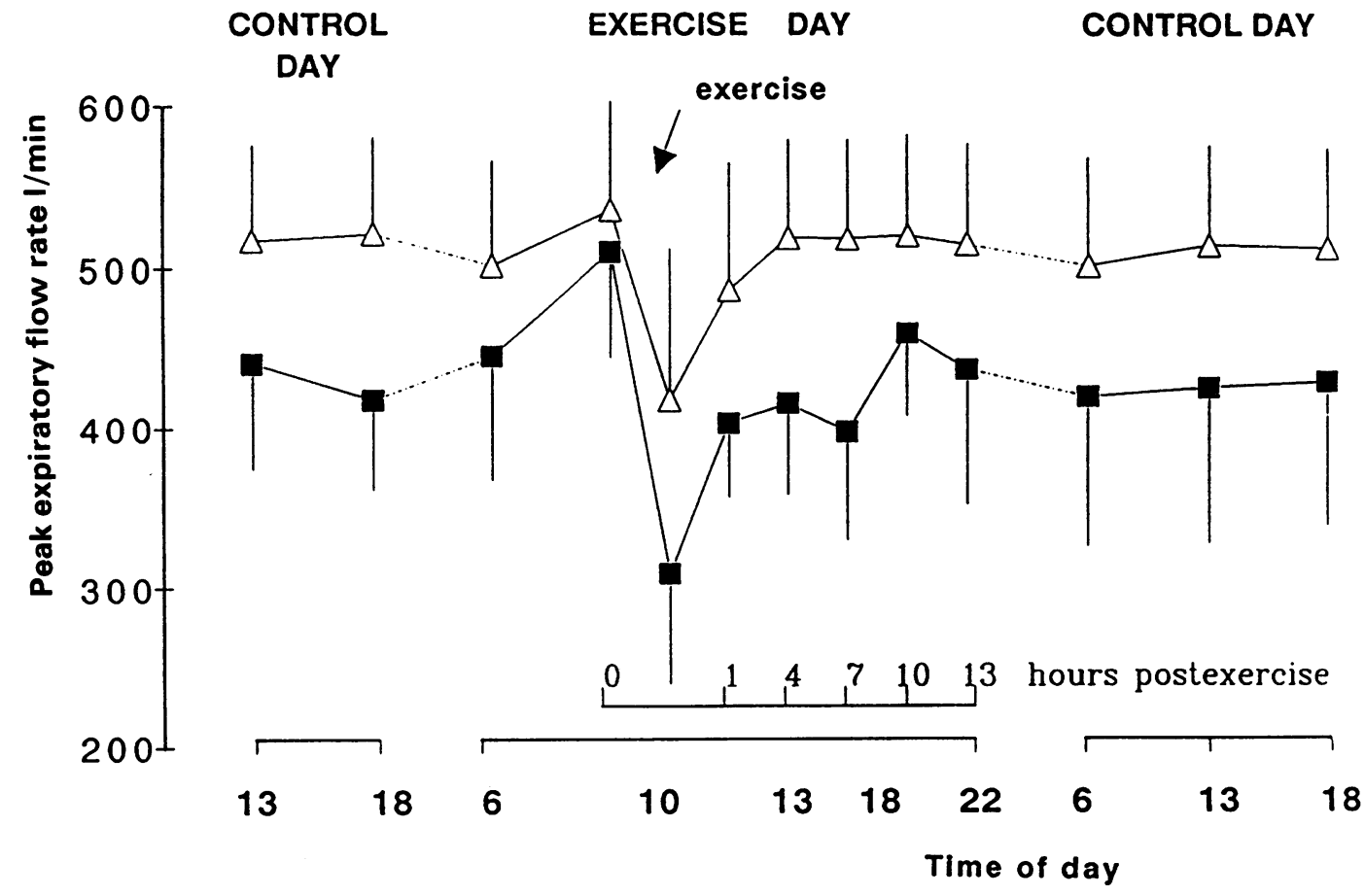


Table 2 Peak expiratory flow (PEF) levels immediately before exercise and the minimum levels during the potential late response period and control period in subjects with a possible "late response" $(n=9)$ and in the remaining subjects $(n=285)$ with exercise induced asthma

\begin{tabular}{|c|c|c|c|c|c|c|}
\hline \multirow[b]{2}{*}{$\begin{array}{l}\% \text { fall in PEF } \\
\text { between } 4 \text { and } 13 \mathrm{~h} \\
\text { after exercise }\end{array}$} & \multirow[b]{2}{*}{$\begin{array}{l}\text { No of } \\
\text { patients }\end{array}$} & \multirow[b]{2}{*}{$\begin{array}{l}\text { Air temperature } \\
\text { during test } \\
\left({ }^{\circ} \mathrm{C} \text {, mean }(S D)\right)\end{array}$} & \multirow[b]{2}{*}{$\begin{array}{l}\text { Immediate } \\
\text { reaction } \\
(\% \text { fall })\end{array}$} & \multicolumn{3}{|c|}{$P E F(l /$ min, mean $(S D))$} \\
\hline & & & & $\begin{array}{l}\text { Before } \\
\text { exercise }\end{array}$ & $\begin{array}{l}\text { Minimum 4-13 h } \\
\text { after } \\
\text { exercise }\end{array}$ & $\begin{array}{l}\text { Minimum } \\
\text { during } \\
\text { control days }\end{array}$ \\
\hline $\begin{array}{l}<20 \\
\geqslant 20\end{array}$ & 285 & $3(12)$ & $26(14)$ & $536(68)$ & $501(61)$ & $476 \quad(87)$ \\
\hline
\end{tabular}

found, though an early obstructive postexercise response was seen in $73 \%$ of the subjects. An apparent late response in some subjects appears to be due to within day fluctuations in pulmonary function, pre-exercise bronchodilatation, and the fact that some airflow obstruction persists after the exercise test.

Rubinstein and coworkers have suggested that changes in airway function that have been interpreted as a biphasic asthmatic response to exercise may be caused by methodological problems in experimental design. ${ }^{7}$ They proposed that the most important reason for the progressive decline in postexercise pulmonary function is the withdrawal from bronchodilator treatment. In the present study only three of the nine potential late responders took medication regularly, and five used bronchodilators "when needed." The diagnosis of asthma had not been made in the remaining patient at the time of inclusion in the present study. All the nine patients had been admitted to the studies because of clearly aggravated labile asthma, while most of the other patients had more stable asthma and were admitted for assessment of fitness. Patients with deteriorating pulmonary function within hours of an exercise challenge need regular medication as their asthma is unstable.

In this study we found greater pre-exercise bronchodilatation in patients with an apparent late response to exercise. This may be caused by anticipation of the test, causing release of endogeneous catecholamines. Pre-exercise bronchodilatation has not been noted in other studies of the late reaction after exercise, ${ }^{3-711}$ possibly because these studies have analysed only the pulmonary function data measured just before the challenge, during the time of pre-exercise bronchodilatation. Pre-exercise bronchodilatation also gives a plausible explanation for the findings in several previous studies, ${ }^{3-711}$ where pulmonary function did not return completely to the starting value after the early response. When this "hidden" bronchoconstriction was removed by treatment with corticosteroids, no pre-exercise bronchodilatation occurred and no "delayed reaction" was seen after exercise. ${ }^{12}$

The prevalence of even possible late responders was low in our population $3 \%$ of subjects with exercise induced asthma if the limit of a late response is put at a $20 \%$ fall in PEF). Others have reported a much higher prevalence of "late responders" in selected study populations-for example, $15 \%,{ }^{7} 33 \%,{ }^{4}$ and even $54 \% .{ }^{13}$ One reason for this discrepancy may be the different study populations. A late response after exercise has been found in children ${ }^{45}$ and mediator release was found during the late response. ${ }^{4}$ Another reason for the discrepancy, however, may be that the pre-exercise bronchodilatation has escaped notice in other studies.

Exercise tests were undertaken under natural ambient air conditions, which varied rather more widely than in a controlled environment. Our results are likely to reflect the everyday occurrence of a late asthmatic response in a population of young men with mild or moderate bronchial asthma. The nine subjects who were potential late responders also exercised in very different climatic conditions (from $-10^{\circ} \mathrm{C}$ to $+22^{\circ} \mathrm{C}$ ), but the mean temperature during their tests was similar to that seen during the other tests (table 2). The study group was large, so a certain kind of climatic environment is unlikely to be necessary for a late response to occur.

Many variables, such as the underlying state of airway reactivity modified by allergen exposures, may change the reactivity to exercise. ${ }^{14} 15$ This may partly explain why exercise responses on warm summer days were almost of the same magnitude as those on cold and dry winter days despite the controlled work load during the tests.

This study strongly supports the view that the delayed response to exercise is an artefact, $^{216}$ at least in young men with mild or moderate asthma. The absence of a late response in exercise induced asthma suggests that there are differences in the pathophysiology of exercise induced and allergen induced asthmatic reactions. This is clinically important, as exercise cannot be blamed for continuous aggravation of the asthmatic state. On the contrary, such a deterioration may be due to other factors, such as prolonged or repetitive late allergic reactions.

This study was supported by a grant from Finnish Defence Forces. I thank Dr Lauri A Laitinen for his helpful comments.

1 Bierman CW. A comparison of late reactions to antigen and exercise. $J$ Allergy Clin Immunol 1984;73:654-9.

2 McFadden ER Jr. Exercise and asthma. $N$ Engl $J$ Med 1987;317:502-4.

3 Bierman CW, Spiro SG, Petheram I. Late response in exercise-induced asthma [abstract]. J Allergy Clin Immunol 1980;65:206.

4 Lee TH, Nagakura T, Papageorgiou N, Iikura Y, Kay AB. Exercise-induced late asthmatic reactions with neutrophil chemotactic activity. N Engl J Med 1983;308:1502-5.

5 Iikura Y, Inui H, Nakagura T, Lee TH. Factors predispos- 
ing to exercise-induced late asthmatic responses. J Allergy Clin Immunol 1985;75:285-9.

6 Boulet L-P, Legris C, Turcotte H, Hebert J. Prevalence and characteristics of late asthmatic responses to exercise. $J$ Allergy Clin Immunol 1987;80:655-62.

7 Rubinstein I, Levison H, Slutsky AS, et al. Immediate and delayed bronchoconstriction after exercise in patients with asthma. $N$ Engl J Med 1987;317:482-5.

8 Bierman CW. Exercise and asthma. $N$ Engl $J$ Med 1988;318:451.

9 Lee TH, Kay AB, Nagakura T, Iikura Y. Exercise and asthma. $N$ Engl J Med 1988;318:452.

10 Anderson SD, Silverman M, König P, Godfrey S. Exerciseinduced asthma. $\mathrm{Br} J$ Dis Chest 1975;69:1-39.

11 Horn CR, Jones RM, Lee D, Brennan SR. Late response in exercise-induced asthma. Clin Allergy 1984;14:307-9.
12 Bierman CW, Spiro SG, Petheram I. Characterization of the late response in exercise-induced asthma. $J$ Allergy Clin Immunol 1984;74:701-6.

13 Feldman CH, Fox J, Kraut E, Feldman BR, Davis WJ Excrcise induced asthma (EIA): treatment for early and late responses [abstract]. Am Rev Respir Dis 1982;125(suppl): 195 .

14 Godfrey S. Controversies in the pathogenesis of exerciseinduced asthma. Eur J Respir Dis 1986;68:81-8.

15 Karjalainen J, Lindqvist A, Laitinen LA. Seasonal variability of exercise-induced asthma especially outdoors. Effect of birch pollen allergy. Clin Exp Allergy 1989;19:273-9.

16 Zawadski DK, Lenner KA, McFadden ER Jr. Re-examination of the late asthmatic response to exercise. Am Rev Respir Dis 1988;137:837-41. 